\title{
PATRIMONIO CULTURAL INMATERIAL Y SUSTRATO BIOCULTURAL EN PAISAJES DE SAN PEDRO DE ATACAMA, REGIÓN DE ANTOFAGASTA Y RÍO IBÁÑEZ, REGIÓN DE AYSÉN
}

INTANGIBLE CULTURAL HERITAGE AND BIOCULTURAL SUBSTRATE IN LANDSCAPES OF SAN PEDRO DE ATACAMA, ANTOFAGASTA REGION AND RÍO IBÁÑEZ, AYSÉN REGION

Fecha recepción: 21 de septiembre de 2020 / fecha aceptación: 29 de diciembre de 2020

Dr. Roberto Gabriel Concha Mathiesen ${ }^{1}$

Cómo citar este artículo:

Concha, R. (2020). Patrimonio cultural inmaterial y sustrato biocultural en paisajes de San Pedro de Atacama, Región de Antofagasta y Río Ibáñez, Región de Aysén. Revista Pensamiento y Acción Interdisciplinaria, 6(2), 31-49. http://doi.org/10.29035/pai.6.2.31

\section{Resumen}

En este artículo se aborda el patrimonio biocultural como sustrato del Patrimonio Cultural Inmaterial (PCl) a la vez que se analiza su interrelación con las dinámicas de paisajes culturales vivos. Para ello se utilizan antecedentes del pueblo lican antai en San Pedro de Atacama, Región de Antofagasta, y de colonos que habitan en la cuenca del Río Ibáñez, Región de Aysén. Se plantea que la viabilidad del $\mathrm{PCl}$ se basa en encadenamientos bioculturales. El patrimonio biocultural es entendido como un meta-patrimonio ya que es relevante para la continuidad y viabilidad del $\mathrm{PCl}$. Medidas de salvaguardia deben implicar la reproducción de condiciones ecosistémicas y prácticas culturales, que constituyen parte fundamental del paisaje vivo. En particular, se analiza la comunidad como organización en la cual se sostiene las manifestaciones culturales vivas del pueblo Lican antai; y el conocimiento local como base de la cultura viva en la cuenca del Río Ibáñez.

Palabras clave: Patrimonio Cultural Inmaterial, Patrimonio Biocultural, Paisaje Cultural, pueblo lican antai, Río Ibáñez

1 Lic. en Antropología, PhD en Gestión de la Cultura y el Patrimonio (U. de Barcelona), Director Regional en Araucanía del Servicio Nacional del Patrimonio Cultural. Correo electrónico: roberto.concha@patrimoniocultural.gob.cl 


\begin{abstract}
This paper addresses the biocultural heritage as a substrate for the Intangible Cultural Heritage (ICH) while analyzing its interrelation with the dynamics of living cultural landscapes. For this purpose, antecedents of the lican antai People in San Pedro de Atacama, Antofagasta Region, and of settlers living in the Ibáñez River basin, Aysén Region arepresented. It is argued that the viability of $\mathrm{PCl}$ is based on biocultural linkages. Biocultural heritage is understood as a meta-heritage since it is relevant for the continuity and viability of ICP. Safeguard measures must imply the reproduction of ecosystem conditions and cultural practices, which constitute a fundamental part of living landscapes. In particular, community is analyzed as an organization in which living cultural manifestations of lican antai people are sustained; and local knowledge as the basis of living culture at Ibáñez River basin.
\end{abstract}

Keywords: Intangible Cultural Heritage, Biocultural Heritage, Cultural Landscape, lican antai people, Ibáñez River

\title{
Introducción
}

El artículo presentado a continuación tiene como objetivo ilustrar la interrelación entre el patrimonio biocultural, entendido como sustrato del patrimonio cultural inmaterial, y las dinámicas de los paisajes culturales vivos. Se utilizan antecedentes de comunidades lican antai en San Pedro de Atacama, Región de Antofagasta, y de colonos en Río Ibáñez, Región de Aysén, los cuales fueron recogidos en el marco de estudios realizados por ONG Poloc durante 2012-2013 (Concha, 2013) y 20182019 (Molina \& Concha, 2019), en los cuales participó el autor como investigador.

En el primer caso, el autor realizó un estudio de la variable "Conocimientos asociados al paisaje: Temporalidades y espacialidades"; en el segundo caso el autor investigó el concepto de comunidad lican antai. En ambos casos, se utilizaron herramientas del método etnográfico para la recolección y análisis de datos, a partir de trabajo de campo.

\section{Aproximación teórica}

El concepto de 'paisaje cultural', en su acepción más común, es entendido como un territorio donde la naturaleza ha sido transformada por la cultura (Fowler, 2003). Así, en la Convención Sobre Patrimonio Mundial ya se hablaba de "obras conjuntas del hombre y la naturaleza" (UNESCO, 1972), y a partir de 1992, UNESCO utiliza esa definición para referirse a los paisajes culturales, entendidos además como lugares "ilustrativos de la evolución de la sociedad humana y sus asentamientos a través del tiempo, bajo la influencia de las limitaciones y/o las oportunidades físicas que presenta su entorno natural y de las sucesivas fuerzas sociales, económicas y culturales, tanto externas como internas"2 (UNESCO, 2011, p. 14). De acuerdo con las Orientaciones Operacionales para la Implementación de la Convención de Patrimonio Mundial, existen tres categorías de paisaje cultural 
(UNESCO, 1999, p. 9): i) paisaje concebido, creado intencionalmente por el hombre; ii) paisaje orgánicamente evolutivo, que puede ser fósil o en estado vivo; y iii) paisaje cultural asociativo, resultante de los significados que se le asignan a los elementos que lo componen. Para este artículo nos interesa en particular la categoría de Paisaje Vivo, donde la evolución orgánica está en curso.

Posteriormente, se ha propuesto la categoría de 'paisajes lineales', que se subdivide en 'canales' e 'itinerarios culturales' -estos últimos implican recorridos que se reiteran en el tiempo como expresión de una práctica cultural, con intercambios que responden a una función religiosa, comercial y/o administrativa (Rössler, 1998).

El concepto de paisaje cultural no sólo se aplica a sitios que destacan por su excepcionalidad sino también a otros espacios analizados, que conjugan naturaleza y cultura. En este sentido, Avocat define el paisaje como cualquier "porción de espacio analizado [...] resultante aparente y percibido de un conjunto de funciones y relaciones entre los elementos físicos, biológicos y antropológicos que constituyen el medio de vida"3 (Avocat, 1984, p. 11). En el mismo sentido, el Convenio Europeo del Paisaje (Consejo de Europa, 2000), señala que cualquier porción de territorio cuyo carácter es el resultado de la interacción de factores naturales y/o humanos, puede ser reconocida, estudiada y gestionada como paisaje, independientemente de su valor.

En síntesis, el paisaje cultural puede ser entendido como ensamble entre la fisonomía de un territorio (huella de factores naturales y antrópicos) y la percepción sensorial de los observadores (habitantes, investigadores, visitantes), quienes están condicionados por factores culturales y biográficos.

Tradicionalmente han sido especialistas (paisajistas, arquitectos, geógrafos, ecólogos) los encargados de describir y evaluar el paisaje desde ciertos marcos referenciales; sin embargo, nuevas propuestas epistemológicas confieren protagonismo a los usuarios del paisaje en la distinción y valoración de sus componentes.

El modelo de valores culturales del paisaje de Stephenson (2008), considera especialmente la percepción de los habitantes, quienes juegan un importante rol en la resiliencia del paisaje. El modelo de Stephenson agrupa los valores culturales asignados al paisaje en tres conjuntos: formas, prácticas/procesos y relaciones. 


\section{Figura 1}

Relaciones, Prácticas y Formas en el Modelo de valores culturales de Stephenson.

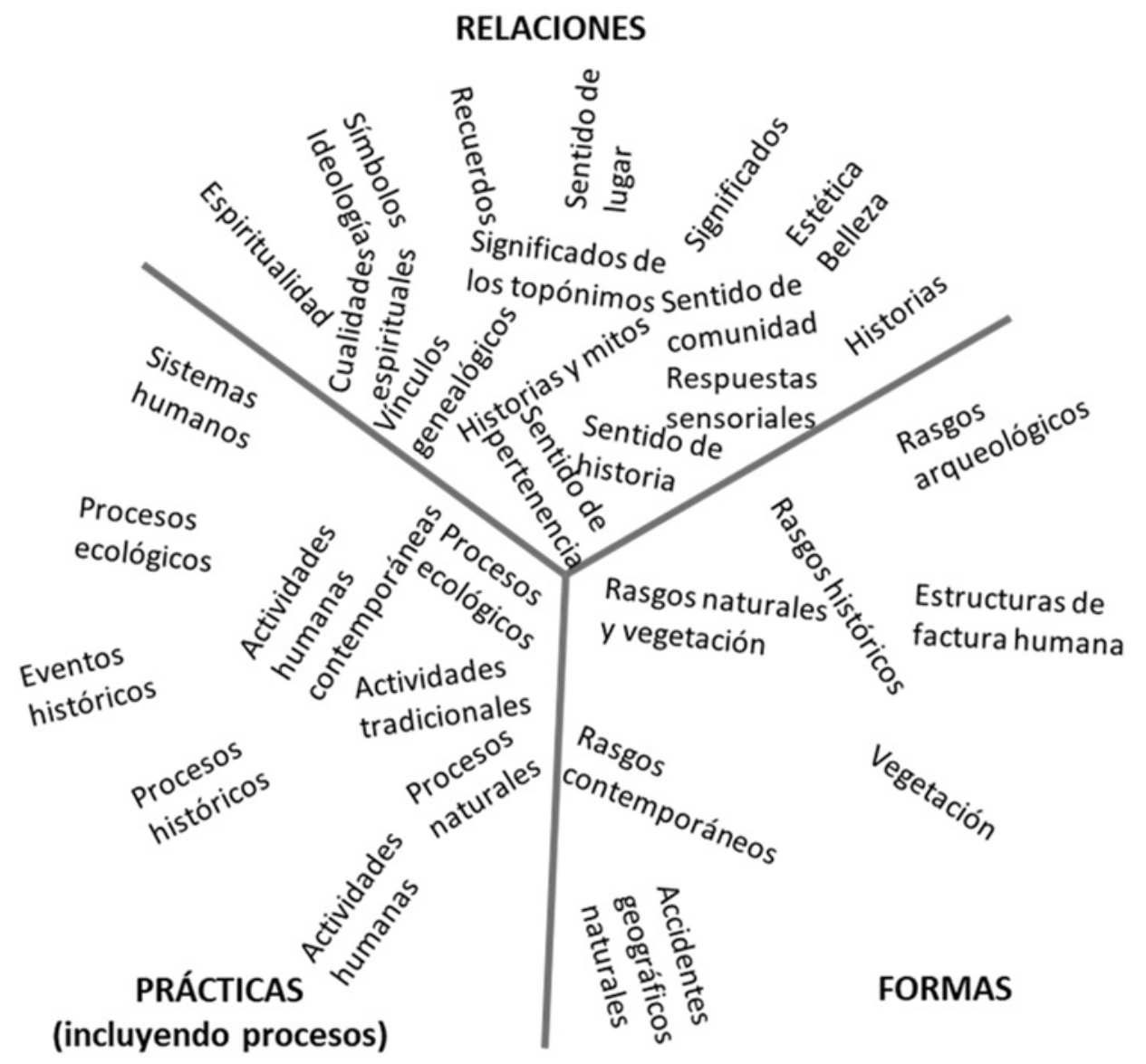

Fuente: Stephenson, 2008, p. 134 (original en inglés).

Las tres subdivisiones propuestas por Stephenson dan cuenta de significaciones asignadas por la población a los elementos del paisaje. En primer lugar, se le asignan significados y valor a las formas presentes en el paisaje, aquello que es accesible a la observación y en un sentido más amplio a la percepción. En segundo lugar, están los significados y valor asignados a las prácticas y procesos humanos, así como de la naturaleza -dinámicas del paisaje. En tercer lugar, está el vínculo de las personas con los elementos de su hábitat, las asociaciones que se establecen entre la identidad individual y colectiva con los lugares.

Este modelo puede ser complementado con las percepciones de quienes visitan, estudian y reflexionan sobre el paisaje sin necesariamente ser habitantes, 
valorando especialmente aquello que perciben como elementos extra culturales (Prats, 1998): lo que proviene de otro tiempo, otro espacio o del genio humano, ajeno a lo cotidiano. Aquello que ha permanecido en el tiempo, lo nativo, prístino, único, es susceptible de ser valorado especialmente en el paisaje. En consecuencia, el territorio opera como continente de significados para distintos usuarios del paisaje, evocando contenidos y emociones.

A ciertos elementos del paisaje, tangibles e intangibles, se les asigna valor patrimonial y se les reconoce como foco de contemplación y veneración. Son seleccionados en función de criterios, intereses y mecanismos que operan desde el presente, destacando sus cualidades distintivas e irremplazables (Prats, 1997). Dado el alto valor que se les asigna, se gestiona su uso, investigación y conservación para que sean una herencia a las futuras generaciones (Balart y Tresserras, 2008). Con la declaración de patrimonio se busca poner en valor y gestionar los elementos seleccionados.

Figura 2

Niveles en que opera la patrimonialización.

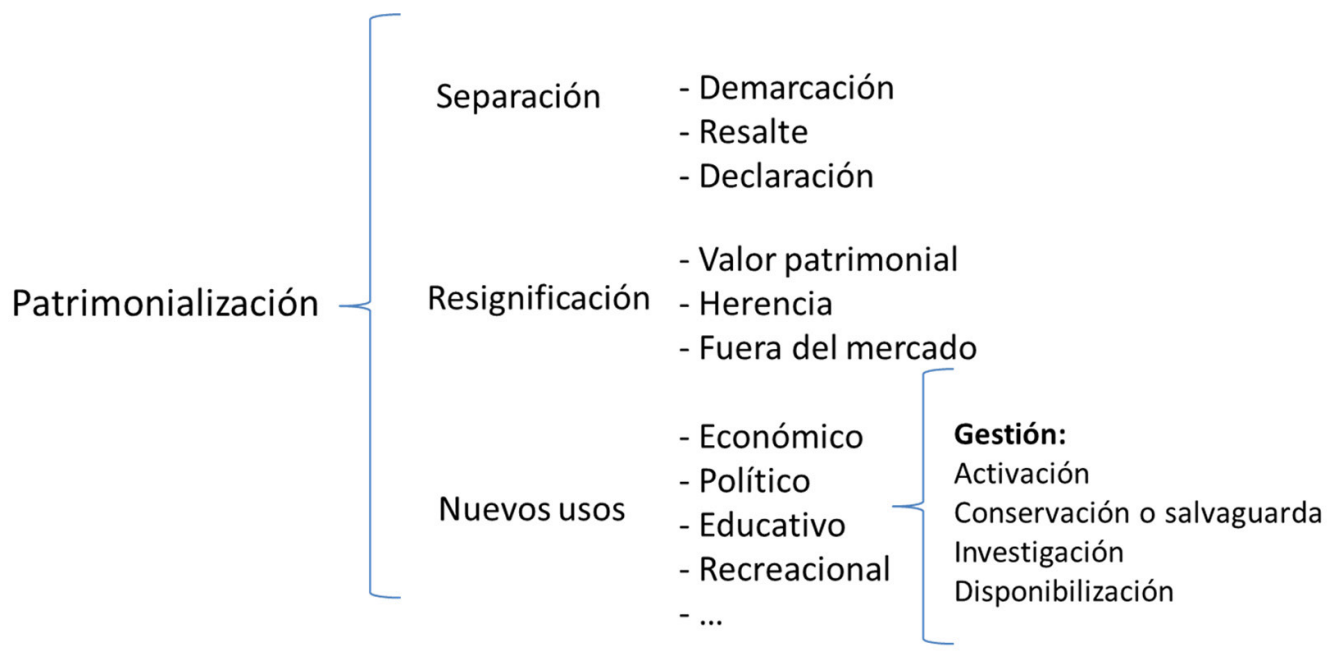

Fuente: Elaboración propia.

Los países que han adscrito a la convención de UNESCO sobre patrimonio mundial adoptan en sus legislaciones nacionales tipologías de patrimonio que se estructuran en tres ejes: naturaleza/cultura; material/inmaterial; mueble/ inmueble. En Chile, el Servicio Nacional del Patrimonio Cultural (SERPAT) cuenta con una Subdirección de Patrimonio Cultural Inmaterial (PCI) que a su vez se apoya en un Comité Asesor para el reconocimiento de manifestaciones culturales como $\mathrm{PCl}$, a partir de solicitudes ciudadanas. El SERPAT también cuenta con 
una secretaría ejecutiva de Monumentos Nacionales y con Oficinas Técnicas Regionales, que velan por los distintos tipos de monumentos (elementos muebles e inmuebles, incluidos santuarios de la naturaleza) bajo el mandato del Consejo de Monumentos Nacionales. El SERPAT además cuenta con Subdirecciones y redes de Bibliotecas, Archivos y Museos que gestionan colecciones bibliográficas, documentales y de piezas (elementos muebles). El Sistema Nacional de Áreas Silvestres protegidas (SNASPE) es el principal referente de Patrimonio Natural, gestionado por la Corporación Nacional Forestal (CONAF), mientras que el Servicio Nacional de Pesca y Acuicultura (SERNAPESCA) se encarga de las áreas marinas protegidas.

Los Estados parte de la Convención UNESCO sobre patrimonio mundial proponen elementos que ya han sido reconocidos como patrimonio relevante a nivel nacional, para que se incorporen a la lista de Patrimonio Mundial. Por su parte, UNESCO ha adoptado progresivamente un enfoque participativo para qua las comunidades vinculadas al elemento patrimonial se involucren en el proceso de declaración.

Pese a la separación entre patrimonio natural y patrimonio cultural, el sistema clasificatorio de UNESCO ha permitido incluir en la lista de patrimonio mundial a elementos que combinan naturaleza y cultura, como patrimonio mixto y como paisajes. A su vez, se asume que los elementos de patrimonio material o tangible están cargados de contenidos y significados, por lo tanto, conllevan una dimensión intangible. También las manifestaciones de patrimonio cultural inmaterial se expresan y están asociadas a elementos tangibles, por lo tanto, estas categorías en ningún caso son excluyentes, pero contrastan en algunos aspectos fundamentales señalados a continuación: 


\section{Figura 3}

Cuadro comparativo de patrimonio cultural material e inmaterial.

Patrimonio Cultural Material

Se asigna valor patrimonial a elementos tangibles ya sean éstos de carácter mueble (piezas arqueológicas, históricas, etnológicas, paleontológicas), o inmueble (edificaciones, sitios arqueológicos o lugares de memoria).
Patrimonio Cultural Inmaterial

El valor patrimonial está en manifestaciones intangibles tales como conocimientos y prácticas, ritos, artes escénicas, oficios, tradiciones orales.
Autenticidad del elemento implica presencia de características y/o materiales originales y explicitación de aquello que se ha incorporado con posterioridad, ya sean transformaciones, reconstrucciones o restauraciones.

\begin{abstract}
Autenticidad del elemento implica que se expresa como es en el presente y no depende de que se mantengan elementos originales. Se trata de cultura viva (dinámica), lo que implica una cierta profundidad histórica (más allá de una generación).
\end{abstract}

La gestión implica conservar la autenticidad, originalidad e integralidad del elemento.
La gestión implica medidas de salvaguardia para propiciar la continuidad de condiciones bioculturales que hacen viable al elemento.

Fuente: Elaboración propia.

El Patrimonio Cultural Inmaterial, al definirse como cultura viva, requiere de una continuidad en las condiciones bioculturales que posibilitan su viabilidad. Así por ejemplo, si se busca impulsar la salvaguardia de la carpintería de ribera, se requiere de condiciones para que los cultores puedan transmitir su conocimiento y técnicas a otros; para que dicha actividad sea sostenible ambiental y económicamente; para que estén disponibles las materias primas necesarias, que las embarcaciones sigan siendo una solución eficiente, que haya cultores y usuarios, etc. En tal sentido, podemos hablar de encadenamientos bioculturales del patrimonio inmaterial, lo que lleva a la noción de patrimonio biocultural, entendido como:

...conocimiento, innovaciones, prácticas y expresiones culturales de pueblos indígenas y comunidades locales que comparten colectivamente y se vinculan de manera inextricable a los recursos y territorios, incluyendo la diversidad de genes, variedades, especies y ecosistemas; valores culturales y espirituales; leyes consuetudinarias formadas dentro del contexto socioecológico de comunidades. (Millaleo, 2013, p. 95). 
Se trata de elementos bioculturales a los cuales se les asigna valor patrimonial y que son clave para la viabilidad y salvaguardia de ciertas manifestaciones de $\mathrm{PCl}$ así como para la resiliencia de los paisajes culturales, por lo tanto, se puede entender como un meta-patrimonio.

\section{Figura 4}

Encadenamientos bioculturales del PCl.
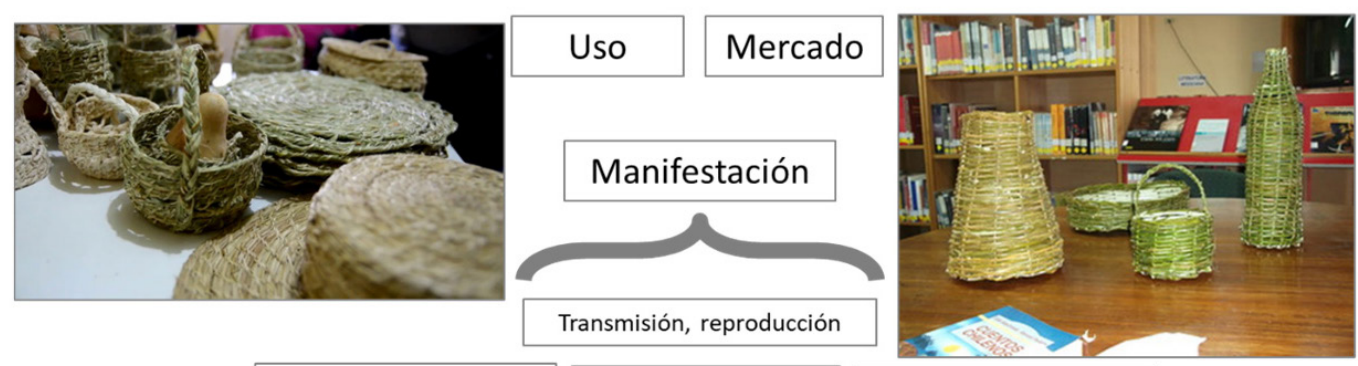

\section{Prácticas}

Instituciones

Vínculos sociales

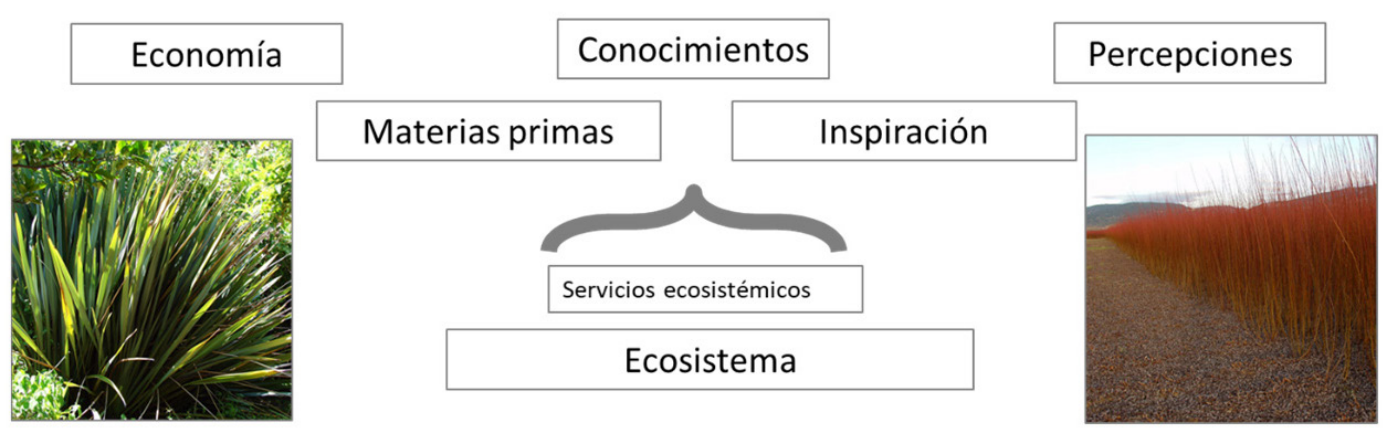

Fuente: Elaboración propia. 


\section{Revisión de casos}

\section{a) La comunidad lican antai en San Pedro de Atacama}

Los Atacameños o lican antai son uno de los nueve pueblos originarios reconocidos inicialmente por el Estado Chileno mediante la Ley Indígena 19.253. ${ }^{4}$ Sus ancestros arribaron hace más de 10.000 años a lo que es hoy la región de Antofagasta, en el norte de Chile, dejando petroglifos y geoglifos para señalar rutas caravaneras entre oasis y quebradas; aldeas y ayllu como formas de asentamiento en torno a las fuentes de agua; infraestructura vial, residencias y fortificaciones, así como diversas obras para el cultivo y la crianza de animales, aprovechando con eficiencia el agua en un ecosistema con escasas precipitaciones. Dichos vestigios dan cuenta de un nivel complejo de organización social y conocimientos profundos acerca del territorio, muchos de los cuales se han transmitido y adaptado hasta el presente.

Actualmente, la población lican antai se concentra en las comunas de San Pedro de Atacama y Calama, en la Provincia del Loa, con un porcentaje importante residiendo en las cabeceras comunales debido a migración campo ciudad, motivada por la educación de los hijos y el cuidado de los adultos mayores. Sin embargo, algunas comunidades lican antai constituyen relictos vivos de la cultura atacameña, reproduciendo actividades agrícolas y ganaderas ancestrales en zonas aisladas. Allí, la comunidad se expresa en prácticas colectivas que se realizan a lo largo del ciclo anual, como trabajos comunales, festividades y ritos, a los cuales se asocian complejos contenidos culturales. Dichas prácticas reproducen la comunidad en su dimensión simbólica y social, a la vez que permiten mantener una adaptación a las condiciones adversas del territorio: aislamiento extremo, escasez hídrica, inundaciones estivales, actividad sísmica. Las festividades en particular tienen una dimensión emocional que contribuye a reforzar la identidad y los vínculos sociales para abordar de manera colectiva las problemáticas de la comunidad.

El desarrollo de las fiestas religiosas y actividades comunitarias tradicionales como la limpia de canales son expresión de un conocimiento tácito acerca de lo que cada uno puede y debe hacer, así como de las conductas inapropiadas que son sancionadas. Así mismo, se basan en sistemas de cargos asumidos por los propios comuneros que les otorgan autoridad para ejecutar normas en distinto momentos y ámbitos, con gran autonomía respecto de entidades externas.

La pertenencia a la comunidad está determinada por el acceso a la tierra y al agua, así como por el cumplimiento de los deberes que ese acceso impone a los comuneros. El comunero debe participar en los trabajos comunales regulares, trabajos de emergencia y celebraciones tradicionales; asistir a las reuniones

4 Posteriormente el marco jurídico chileno reconoce a los afrodescendientes y está en trámite la incorporación de los changos. 
ordinarias y extraordinarias de la comunidad, pagar cuotas, colectas y multas, así como mantener y cuidar las costumbres y tradiciones.

Se accede a la tierra por herencia pero también existe la posibilidad de que personas externas adquieran terrenos mediante compra y se incorporen como nuevos comuneros, en la medida que sean aceptados y cumplan con las obligaciones instauradas por la comunidad.

Mediante la Junta de Vecinos y la Comunidad Indígena se configura una suerte de gobierno local con altos niveles de autonomía, que dispone de un presupuesto discrecional, al mismo tiempo que administra el territorio y el agua. La organización pide y ofrece préstamos, invierte, define gastos, planifica obras, distribuye tierras y asigna el agua, resuelve conflictos, establece normas y aplica sanciones, prescindiendo por largos períodos de tiempo de la injerencia del Estado, que tenía una débil presencia en el territorio hasta la década de 1980. En las asambleas se abordan cuestiones de un ámbito eminentemente secular, ya que la ritualidad opera de acuerdo con una estructura y convenciones tácitas, que no requieren ser explicitadas.

La mantención de actividades agrícolas y ganaderas en el territorio más amplio de la comunidad determina una vigencia de la ritualidad en sus dimensiones propiciatoria y de agradecimiento en la producción. A su vez, implica recorrer y habitar las vegas y estancias productivas, al menos temporalmente, lo que actualiza el vínculo con el territorio. El uso turístico del patrimonio local también está presente, con la transformación de sitios arqueológicos y atractivos naturales en espacios habilitados para recibir visitantes.

Las normas claves para la reproducción y funcionamiento comunitario están basadas en el compromiso de cada comunero para:

- Respetar la asistencia obligatoria y en persona a todas las reuniones ordinarias y extraordinarias llamadas por la comunidad.

- Respetar y hacer respetar los acuerdos de asamblea.

- Llevar al día los libros de actas y hacer cumplir la lectura del acta en cada reunión como agenda de gobierno comunitario.

- Participar de los trabajos comunales.

- Cancelar y estar al día en el pago de todas las cuotas sociales u organizacionales.

- Cancelar las multas impuesta por faltas o comportamientos reñidos con la convivencia comunitaria. 
En consecuencia, todos los miembros de la comunidad deben participar de los trabajos comunales y estar dispuestos a asumir cargos de reciprocidad comunitaria en las fiestas y celebraciones, como ser alférez o capitanes en la limpia de canales.

La comunidad impone restricciones al registro y la divulgación de sus conocimientos y prácticas culturales, las cuales son manejadas con estricta reserva ante observadores externos y se exige autorización para utilizar y difundir información específica de una comunidad. Por esta razón, en este artículo sólo se abordan cuestiones generales que son observables en algunas comunidades lican antai, existiendo también comunidades menos tradicionales que se constituyen y operan como organizaciones funcionales.

El concepto de comunidad lican antai expuesto hasta aquí corresponde a una reconstrucción realizada mediante la lectura con la comunidad de libros de actas que abarcan un período de 4 décadas por lo tanto, refleja lo que efectivamente se discutía en la comunidad, sin embargo, la reconstrucción implica un ejercicio de modelación que lleva a un tipo ideal de organización. En la práctica, ninguna comunidad se va a ajustar de manera exacta con el modelo ya que son versiones de una estructura organizacional que puede variar o implementarse parcialmente.

\section{b) Habitantes de la cuenca del Río Ibañez}

El Río Ibáñez, en la región de Aysén, abarca desde la cumbre del volcán Hudson hasta el lago General Carrera, Ilamado Chelenko en lengua nativa (aguas tempestuosas). Los actuales habitantes de la cuenca son en gran parte descendientes de colonos que Ilegaron hace poco más de un siglo, provenientes del sur de Chile y de Patagonia Argentina, adaptándose a un territorio agreste y aislado, con condiciones geográficas extremas pero que a su vez permite el desarrollo de actividades agrícolas y ganaderas. La adaptación de los colonos a este territorio implicó el desarrollo de un conocimiento local que ha sido transmitido hasta el presente.

El conocimiento local es aquel desarrollado de generación en generación por un grupo humano a partir de, y referido a, su entorno, derivado de su relación permanente con el mismo (Turner \& Berkes, 2006). Es un acumulativo de conocimientos, prácticas y creencias que se transmite de generación en generación, pero es también dinámico, ya que se trata de saberes adaptativos que permiten responder a las transformaciones que afectan al grupo social (Berkes, 2009). Implica una forma propia de entender el tiempo y el espacio local.

La transmisión del conocimiento local entre los habitantes de la cuenca del Río Ibáñez se ha dado principalmente de padres a hijos, a través de la comunicación interpersonal y las experiencias compartidas con vecinos, amigos o familiares. No obstante, este tipo de conocimiento tiene cada vez menos vigencia para las 
nuevas generaciones, en parte porque los adolescentes deben migran a la capital regional para completar su educación escolar ya que en Río Ibáñez sólo se imparte educación básica.

Los actuales pobladores de la cuenca mantienen una relación cultural, económica y social con un amplio territorio, que abarca otras comunas de Aysén, así como otras regiones de Chile y Argentina. Así, logran comprender y caracterizar espacios locales en comparación con diversas zonas, para dar cuenta de sus cualidades. Se reconocen las dificultades y potencialidades de cada espacio, en función de sus características ecosistémicas tales como relieve, microclima, calidad de la tierra, flora y fauna.

Los habitantes de la cuenca reconocen como zonas apropiadas para la agricultura aquellas con una media de temperatura más cálida que en el resto de la cuenca, donde es moderada la oscilación térmica, existen fuentes de agua para el riego que resistan los descensos de nivel propios del invierno y las sequías del verano, y con suelos fertilizados por la ceniza de antiguas erupciones del Volcán Houdson. Los microclimas se dan principalmente cerca de cuerpos de agua como lagos y lagunas. En cuanto al viento, se considera nocivo para la producción de frutales porque daña las flores de los árboles, pero en la localidad de Puerto Ibáñez ayuda a limpiar el aire contaminado por el humo de las estufas a leña y se aprovecha en la limpieza de granos ("aventar").

Los mejores campos para la ganadería son aquellos ubicados en la parte alta de la cuenca donde es posible mantener ganado vacuno y caballar, por la existencia de forraje, agua y las condiciones aptas para cultivar pasto. A estos campos se suman las zonas de veranada que se localizan, en general, en las partes altas o áreas de cordillera (más de 800 - 1000 m.s.n.m) donde durante el verano se mantiene la humedad suficiente para conservar los pastos, mientras que las invernadas se realizan en las costas más bajas de ríos y lagos, donde la nieve del invierno no alcanza a tapar los pastos.

Diversos sectores de la cuenca cuentan con zonas de invernada y veranada en función de la altitud, excluyendo los "cordones" enmarañados de cordillera que no son aptos para pastoreo. Tanto para la agricultura como para la ganadería, se requieren terrenos despejados donde la sombra no afecte los cultivos y permita crecer los pastos. No obstante, la cercanía de zonas boscosas se considera necesaria para la estabilidad de las fuentes de agua y de los suelos. A su vez, ciertas especies de árboles como el maitén y la lenga permiten el ramoneo de los animales, lo cual es conveniente en tiempos y zonas de invernada, cuando el forraje se puede agotar.

Por otro lado, esta misma cercanía de los bosques supone un riesgo para la ganadería porque en ellos habitan animales como el puma y el zorro, especies 
cazadoras que habitan principalmente en sectores altos pero que incursionan cada vez más en los valles y sitios poblados.

En la agricultura se percibe como amenaza a las especies que son maleza, o pastos no controlados que invaden los cultivos, como el trébol gigante que afecta a la alfalfa.

Cuando el ganado no cuenta con fuentes de agua y debe desplazarse para su hidratación, se perjudica la productividad ya que los animales pierden peso y se reduce su producción de leche, especialmente en el caso del ganado vacuno.

Los campos que tienen vocación para la crianza de ovejas (lanar) están un peldaño más abajo que aquellos aptos para el ganado vacuno y caballar, en la valoración que hacen los habitantes de la cuenca. Por último, están los campos que se consideran malos, que por lo general se utilizan para la crianza de caprinos. En estos últimos el agua suele ser escasa, el relieve disparejo y no se encuentran extensiones importantes de pastos. Los campos que presentan bardas o barrancos se consideran peligrosos para el ganado y solo se destinan a la crianza de caprinos.

En el uso de los terrenos también se consideran riesgos ya sea por inundaciones, por una eventual nueva erupción del volcán Hudson (las últimas fueron en 1972 y 1992) y, en menor medida, por posibles derrumbes e incendios. Por otro lado, sitios donde han ocurrido incendios se consideran apropiados para la extracción de leña e incluso para cultivos, por la fertilización ocurrida en los suelos.

Por último, en la valoración de terrenos destinados a actividades productivas también se considera la accesibilidad. En zonas aisladas se dificulta la comercialización del ganado, la extracción de leña o la introducción de maquinaria agrícola, mientras que las zonas mejor conectadas sacan ventajas comerciales de esta situación.

Los habitantes de la cuenca del río Ibáñez realizan un monitoreo constante del clima y el comportamiento de las aguas, la calidad de los suelos, las amenazas representadas por especies nativas e introducidas y las plagas. Se le da especial importancia a la acumulación de nieve porque se ha observado el papel que juega en la disponibilidad de agua para riego y consumo, y en la humedad general de los suelos en el territorio.

El comportamiento de las nieves y la lluvia se monitorea principalmente a partir de la observación de las aguas lóticas, ${ }^{5}$ atendiendo a si suben o bajan los caudales y fijándose en la emergencia de rocas o vegas que operan como marcadores. Así mismo, el cambio en el color de las aguas permite a los habitantes de la cuenca saber si hay avenidas en las partes altas de los ríos y si la calidad del

5 Se trata de las aguas superficiales corrientes o que fluyen (rápida o lentamente), al contrario de las lénticas, que permanecen quietas en depresiones tectónicas porque no fluyen continuamente. 
agua ha podido sufrir modificaciones. El cambio de color también es producido por el "Didymo", 6 alga considerada como plaga que empobrece el ecosistema acuático.

En general, los habitantes de la cuenca consideran que las lluvias y la nieve han disminuido, y por tanto han bajado los caudales de los ríos y arroyos, así como los niveles de los lagos y lagunas, a la vez que se han reducido las superficies de mallines.

Las condiciones de sequía también se hacen evidentes para los habitantes de la cuenca a partir de la proliferación de algunas especies vegetales que crecen en ambientes secos o semi-secos. Es el caso del "neneo" o los "chabrales", arbustos que provocan una valoración diferente de los campos donde se encuentran porque el primero sirve de alimento para los animales, mientras que el segundo no. Por el contrario, los digüeñes son especies que se asocian a zonas húmedas, especialmente los mallines (si bien se dan principalmente en las costas de los ríos también están presentes en los bajos de campos emplazados a mayor altitud).

La presencia de "pillo pillo" es señal de la fertilidad del suelo ("persigue los campos de tierra fértil") mientras que el "yaqui" es síntoma de suelos pobres en nutrientes. El pino también es asociado a suelos pobres por el efecto que la misma especie produce en ellos.

Especies animales consideradas nocivas (como el puma y el zorro) o plagas (como la liebre e insectos que llegan con el calor) pueden ser identificadas por huellas que dejan en los campos y el daño al ganado o a los cultivos. Para enfrentar éstas y otras amenazas, los habitantes de la cuenca aplican soluciones que son propias de la cultura local, y corresponden a adaptaciones adecuadas a las condiciones del territorio.

Como complemento a la comprensión del espacio, los habitantes de la cuenca tienen un profundo conocimiento de los ciclos que afectan al territorio, ya sea a lo largo del año o de largos ciclos que pueden abarcar varias décadas. Así por ejemplo, se compara el clima actual con condiciones que se presentaron 60 años antes aproximadamente: tiempo más caluroso, escasez de nieve y lluvia, estaciones más marcadas, pero con condiciones más inestables e impredecibles.

Normalmente, las estaciones son menos marcadas, los tiempos de verano más frío y las condiciones climáticas más regulares lo que permite prever lluvias, nieve, avenidas de los ríos o períodos secos.

La apariencia de la vegetación, así como el comportamiento o la aparición de algunas especies de flora y/o fauna son indicadores o evidencias que dan cuenta de cambios en el estado del tiempo (por ejemplo, llegada o término

6 Se trata de la Didymosphenia geminata, alga reconocida en el sur de Chile porque produce un tapiz que invade el fondo de los ecosistemas acuáticos causando graves daños a las especies presentes en ellos. 
de la temporada de lluvias), ya sea por el paso normal de las estaciones o por condiciones excepcionales, incluso por catástrofes naturales. A su vez, en cada sector de la cuenca los ciclos climáticos se expresan con matices, variando los meses en que se extienden períodos de lluvias y meses secos; períodos de viento y períodos de nieve.

El monitoreo de la lluvia es importante para planificar las actividades agrícolas, tales como sembrar y aumentar o disminuir el riego. Controlar la llegada de las nieves es importante para los ganaderos, puesto que deben comenzar a bajar los animales de la veranada antes de los nevazones. Las temporadas de viento son aprovechadas en la limpieza de los granos.

En general, para los habitantes de la cuenca también es importante tener en cuenta la época de derretimiento de las nieves, pues es cuando se dan las grandes avenidas en los ríos, que pueden perjudicar las labores agrícolas, causar daños al ganado o dificultar su traslado.

En síntesis, cada lugar y cada estación presentan riesgos y oportunidades, que son consideradas en las actividades productivas y las prácticas cotidianas. La forma particular de vivir el tiempo que tienen los habitantes de la cuenca así como en general la población de Aysén se expresa en el lema: "quién se apura pierde el tiempo". En la práctica, esto hace inconcebible una visita breve o una conversación meramente utilitaria. El tiempo se destina a un diálogo lato, donde ambas partes quieren saber del otro, por lo tanto preguntar y escuchar en torno al mate, al fuego y las "tortas fritas". También se asume que durante largos períodos de tiempo la lluvia, la nieve y el frío restringen las posibilidades de desplazarse lejos del hogar.

\section{Análisis y conclusiones}

La revisión de casos permitió exponer elementos bioculturales que son fundamentales para la reproducción de modos de vida en comunidades de San Pedro de Atacama o en la Cuenca del Río Ibáñez.

En el paisaje de San Pedro de Atacama tienen alto valor los sitios de significación cultural identificados por las comunidades, en particular los cerros sagrados y sitios ceremoniales, los lugares de extracción de materias primas, fuentes de agua, los sitios arqueológicos y los lugares donde se realizan actividades agropecuarias. Por su parte, el observador externo puede asignar valor al contraste e integración entre disponibilidad de agua y desierto, visible en los asentamientos humanos de quebradas y oasis. También se le asigna valor al relieve volcánico y de pampas, a las experiencias culturales, a la arquitectura vernacular en tierra (en especial las iglesias), al avistamiento de fauna en los bofedales y a los múltiples vestigios arqueológicos que se pueden encontrar en el territorio. 
En este marco, si el pueblo lican antai quisiera impulsar el reconocimiento como $\mathrm{PCl}$ de algún elemento propio de su cultura (e.g. la limpia de canales; el calendario de fiestas patronales; etc.), sería impensable su salvaguardia sin la reproducción de la comunidad, la ocupación del territorio comunitario y la economía agroganadera tradicional en quebradas y oasis. De lo contrario el elemento patrimonializado deja de ser cultura viva y puede transformarse más bien en patrimonio etnológico alusivo al pasado del grupo local (Quintero, 2009), o en una versión folclorizada del mismo, o simplemente puede pasar al olvido.

En la cuenca del Río Ibáñez, los pobladores asignan valor a lugares del territorio donde es posible habitar y realizar actividades productivas de una manera favorable (por microclima, disponibilidad de agua, accesibilidad, geografía, flora y fauna), en comparación con otros sitios de referencia, considerando las distintas estaciones del año. En cuanto a elementos intangibles valorados por los pobladores destacan sus propias destrezas asociadas al ámbito ganadero y a la relación con el caballo; algunos cultivos locales como el tomate y el damasco; el trabajo en cuero (sogas); la alfarería de Puerto Ibáñez (reconocida en toda la región) y los payadores. Por su parte, el visitante externo es posible que valore mayormente el asado al palo, el acceso a experiencias de vida cotidiana, las fiestas costumbristas, la geomorfología accidentada de los valles (que tienen un origen glaciar); la biodiversidad, la heterogeneidad del paisaje y los sitios arqueológicos con pinturas rupestres.

En el caso de que fuesen patrimonializadas manifestaciones culturales vivas de la cuenca, su salvaguardia debiese implicar la reproducción de un modo de vida local autovalente, ligado al habitar de la cuenca, a la crianza de animales y a los cultivos, que hace pertinente y funcional el conocimiento heredado de los colonos, el cual se va adaptado a través del tiempo. Es este modo de vida el que incluso sirve de inspiración a los payadores. Por su parte, los propios habitantes de la cuenca han iniciado recientemente procesos de retradicionalización, con la realización de fiestas costumbristas donde se escenifican y ponen en valor prácticas culturales del pasado local, las cuales pueden catalogarse como patrimonio etnológico de la cuenca.

Tanto en San Pedro de Atacama como en Río Ibáñez, la migración campo ciudad, como respuesta al aislamiento y a las condiciones insuficientes para estudiantes y adultos mayores, es una amenaza a la continuidad del patrimonio biocultural que sustenta las manifestaciones valoradas tanto por la población local como por los visitantes.

También el asistencialismo del Estado así como de la gran minería, y el creciente sentido de dependencia en la población local respecto de ayudas, amenaza los mecanismos que provee la propia cultura y comunidad local para generar adaptaciones o soluciones para subsistir frente a las condiciones adversas del territorio. 
Otro factor que amenaza al patrimonio biocultural, que está en la base del $\mathrm{PCl}$ y de la reproducción del paisaje, es la generación de barreras en el territorio que limitan el acceso a las distintas zonas y alteran la continuidad del paisaje. Esto ha sido provocado por explotaciones mineras y energéticas (plantas solares) en el norte y por la irrupción de propietarios foráneos en el sur que buscan constituir explotaciones turísticas o ganaderas, o bien fundos de agrado en amplias extensiones del territorio y en torno a cuerpos de agua. Con esto no sólo se limita el tránsito y la vinculación de las personas con el territorio sino que también se afecta la percepción y calidad del paisaje.

La noción propuesta de "encadenamientos bioculturales del PCl" permite visualizar la incidencia que tiene el sustrato cultural y biológico del territorio, así como su interrelación y reproducción, no sólo en la viabilidad de las manifestaciones a las cuales se les asigna valor patrimonial sino que también en la resiliencia del paisaje. Por lo tanto, es una noción que debiese ser incorporada en la gestión del $\mathrm{PCl}$, en las fases de registro, inventario y salvaguardia. 
Patrimonio cultural inmaterial y sustrato biocultural en paisajes de San Pedro de Atacama, Región de

Antofagasta y Río Ibáñez, Región de Aysén por Dr. Roberto Gabriel Concha Mathiesen

\section{Referencias bibliográficas}

Avocat, Ch. (1984). Essai de mise au point d'une méthode d'étude des paysages. En Université de Saint-Etienne (Ed.). Lire le paysage, lire les paysages : Acte du colloque des 24 et 25 novembre 1983 (pp. 11-23). Saint-Etienne.

Berkes, F., Colding, J., \& Folke, C. (2000). Rediscovery of Traditional Ecological Knowledge as Adaptive Management. Ecological Applications, 10, 12511262.

Concha, R. (2020). La disputa por el Parque Nacional Rapa Nui. Estudios Atacameños, (64). https://doi.org/10.22199/issn.0718-1043-2020-0013

Concha, R. (2019). Usos polítics i econòmics del Parc Nacional Rapa Nui (illa de Pasqua, Xile): Patrimoni de la Humanitat. Revista d'Etnologia de Catalunya, (44), 184-190.

Molina, R., \& Concha, R. (2019). Concepto de comunidad Lickanantay: estudio de casos, comunidades de Caspana y Río Grande. Santiago: ONG Poloc/CONADI.

Concha, R. (2013). Caracterización de la Cuenca del Río Ibáñez como Paisaje Cultural. Jangwa Pana 12(1), 52-65.

Concha, R. (2013). Informe de variable "Conocimientos asociados al paisaje: Temporalidades y espacialidades", ONG Poloc. Informe no publicado.

Consejo de Europa (2000). Convenio Europeo del Paisaje. Florencia. Recuperado de http://www.cultura.mecd.es/legislacion/patri/pdf/convenio_euro_ protec_2000.pdf

Fowler, P. J. (2003). World Heritage Cultural Landscape, 1992-2002. París: UNESCO.

Millaleo, S. (2013). Conocimiento mapuche y derechos de propiedad intelectual. En Olea, H. (Ed.) Derecho y Pueblo Mapuche: Aportes para la discusión, (pp. 87-133). Santiago: Universidad Diego Portales.

Prats, LI. (1997) Antropología y patrimonio. Barcelona: Ariel.

Prats, LI. (1998). El concepto de patrimonio cultural. Política y Sociedad, 27, 63-76.

Quintero, V. (2009). Los sentidos del patrimonio: Alianzas y conflictos en la protección del patrimonio etnológico andaluz. Sevilla: Fundación Blas Infante.

Rössler, M. (1998). Los paisajes culturales y la Convección del patrimonio Mundial Cultural y Natural: resultados de reuniones temáticas previas. Recuperado de: http://www.condesan.org/unesco/Cap\%2006\%20metchild\%20rossler. pdf (Consulta 15-X-2013). 
Stephenson, J. (2008). The Cultural Values Model: An integrated approach to values in landscapes. Landscape and Urban Planning 84, 127-139.

Turner, N.J., \& Berkes, F. (2006). Coming to understanding: developing conservation through incremental learning in the Pacific Northwest. Human ecology, 34, 495-513.

UNESCO (1972). Convención sobre la protección del patrimonio mundial, cultural y natural. Recuperado de http://portal.unesco.org/es/ev.php-URL_ ID =13055\&URL_DO=DO_TOPIC\&URL_SECTION=201.html

UNESCO (1999). Operational Guidelines for the Implementation of the World Heritage Convention. Recuperado de https://whc.unesco.org/archive/ opguide99.pdf

UNESCO (2011). Operational guidelines for the implementation of the World Heritage Convention. Recuperado de https://whc.unesco.org/archive/ opguide11-en.pdf

Dirección de correspondencia:

Roberto Gabriel Concha Mathiesen

Contacto: roberto.concha@patrimoniocultural.gob.cl 